\title{
Apes in fiction: does the content of novels reflect primatological knowledge?
}

\author{
William C. McGrew ${ }^{1}$ D
}

Received: 14 December 2020 / Accepted: 20 January 2021 / Published online: 4 February 2021

(C) Japan Monkey Centre 2021

\begin{abstract}
Novels about great apes and humans continue to be consistently popular with the reading public, sometimes reaching bestseller status. Media reviews of these books rarely comment on their primatological roots, nor do primatological journals review them. In a non-quantitative, pilot study, I scrutinize six prominent novels, in terms of three questions: How do the novels make use of primatology? What aspects of primatology do they use? How accurate is their use of primatology? Such novels overwhelmingly concentrate on language, with intelligence and sexuality lagging far behind; other topics, such as culture or technology, receive little or no attention. Apes in nature are rarely mentioned. Inaccuracies abound, even at the most basic level of primatological knowledge that easily could be remedied. Both authors and primatologists would benefit from more informative interaction before publication.
\end{abstract}

Keywords Hominidae $\cdot$ Pan $\cdot$ Gorilla $\cdot$ Chimpanzee $\cdot$ Gorilla

\section{Introduction}

Amongst nonhuman animals, the Order Primates seems to be favored by authors of fiction; amongst primates, the great apes (Hominidae) are similarly more favored (Copeland 2015). The explanation seems simple: Homo sapiens is also a great ape, and the other living genera, Gorilla, Pan, and Pongo, are our nearest extant cousins. Hence, comparison between them and us seems to be irresistible, especially as differences more and more seem to be a matter of degree instead of kind.

Recent fictional interest in great apes has much information to choose from, as primatologists publish more and more about them, in nature or in captivity. For example, study sites of habituated wild chimpanzees continue to increase, and technical advances such as camera-trapping and drones provide more data. Captive great apes are studied in laboratories, zoological gardens, retirement refuges, and rescue sanctuaries. Thus, authors of fiction have more and more accumulated knowledge to choose from in crafting

William C. McGrew

wcm21@cam.ac.uk

Scottish Primate Research Group, School of Psychology and Neuroscience, University of St Andrews, South Street, St Andrews KY16 9AJ, Scotland, UK their works. This is important, as many more lay readers will gain their knowledge or impressions of apes from novels than from journal articles or academic tomes. But how extensive and representative are these fictional portrayals of great apes?

The present, exploratory analysis aimed to answer the following questions:

(1) To what extent do authors make use of the findings of scientific primatology, in the broadest sense?

(2) To what aspects or topics in primatology do they refer?

(3) How accurate is their use of primatological knowledge?

Accordingly, this preliminary analysis is aimed at primatologists, assuming their basic background of the discipline, as informed readers.

\section{Material and methods}

Published (textual, not graphic) novels about great apes, rather than short stories, poems, films, television series, or plays, were chosen for scrutiny. The reasoning was that novels provide more substantial potential for revealing patterns than do shorter or more constrained literary or cinematic efforts. I limited myself to adult fiction, published in 
English (even if published originally in another language). Most important was that the novel must have at least one great ape as a major character, although this role was usually shared with at least one human being.

Selection of the novels was neither random nor systematic; for this preliminary study, I used six books already close to hand (see below, 1-6, presented chronologically). If this pilot project is informative, then more sources may be used in a broader, follow-up study. (Copeland lists at least 40 novels that meet the above criteria in her comprehensive list.) The primary aim was detailed scrutiny and analysis of text, based on careful reading and detailed note-taking following a predetermined but flexible outline: brief description of author and works, precis of plot, primatological topics developed, use of primatology, accuracy of use, accessories, brief summary.

Also, I noted whether the books included 'accessories,' that is, acknowledgements, index, references, footnotes, preface, foreword, or other supplementary information. I noted whether the reverse of a book's title page contained a version of the following Standard Statement: "This book is a work of fiction. Names, characters, businesses, organizations, places, events, and incidents either are the products of the author's imagination or are used fictitiously. Any resemblance to actual persons, living and dead, events, or locales is entirely coincidental." Versions of this boiler-plate assertion appear in half the books, although this bold claim appears to be nonsense. Counterparts to real persons, places, and institutions are given in quotation marks, versus their real-life equivalents, which are not. Finally, a spoiler alert: the results section contains details of the plot development.

\section{Results}

\section{Congo, by Michael Crichton (1980) (C)}

This book was Crichton's fourth best-selling novel combining thriller and science. He therefore publishes science fiction of a sort, but his books are knowledgeable and compelling, skillfully mixing fact and fiction, from The Andromeda Strain onwards. He is particularly good at making use of cutting-edge technology. Perhaps his best-known novel is Jurassic Park, made into a smash-hit feature film that featured ancient DNA and dinosaurs (but only human apes).

The narrative largely covers 13 days of fast-paced, African fieldwork, covering the progress of a geological expedition sent to Zaire (present-day Democratic Republic of Congo), seeking to uncover the fate of its predecessor, which failed inexplicably. The earlier expedition to the Virunga volcanoes region sought precious minerals, and spotty evidence suggests that it met local resistance by unknown forces, perhaps linked to gorillas. For this reason, the follow-up expedition includes a young University of California (Berkeley) professor, Peter Elliot, whose research interest is primate communication, accompanied by his star subject, Amy. Amy is a female mountain gorilla who has learned American Sign Language. The expedition unfolds, with ups and downs, some of which result from fatal competition with a Japanese group, each racing to get to the source of the prized blue diamonds, which are linked to an ancient city, Zinj. Once on site, the expedition members realize that their predecessors were wiped out by locals, of which there is more than one variety. Amy is employed to interact with the local gorillas, who turn out not to be a problem, but there is another species of super-ape that is much more dangerous. These 'grey gorillas' turn out to be the product of interbreeding between Pan and Homo, and they are nocturnal, cooperative killers, who exact their fatal toll on the expedition members. The climax comes when the expedition camp finally is overrun by the super-apes, simultaneous with the huge eruption of the nearby volcano, which buries all traces of the expedition, the city, and the diamonds. Key members of the expedition escape, but Elliot and Amy later return to Zaire, where Amy gradually integrates with local gorillas and eventually disappears into the wild.

Crichton makes clever use of extensive scientific research, interweaving it with imaginary additions. His potted history of 'pongo-linguistics' (pp. 34-38) is perhaps 90\% factual, so much so that it is hard to spot the other $10 \%$, which is not. Sometimes, the alterations are minimal, such that Cathy Hayes and chimpanzee Viki become "Kathy Hayes" and "Vicki." The Gardners get their due, but Roger Fouts is never mentioned. The Rumbaughs and Kanzi also are absent, and the bonobo species is ignored, although it too lives in the DRC. Penny Patterson and Koko are recycled as "Elliot" and "Amy": Wild-born Amy lives in a mobile home in San Francisco. She swears and signs jokes and has a vocabulary of $600+$ words and an IQ of 92 , but she also smokes and detects human lying. She categorizes herself as human, in the famous photo-sorting task of the Hayses (Hayes 1951). All that Crichton writes about wild gorillas comes from the pioneering work of George Schaller; Dian Fossey is mentioned only once in passing. Again and again, Crichton employs credible embellishments, so that primatologically uneducated readers will find it hard to distinguish fact from fiction.

However, the book contains many errors: Gorillas live in 'troops' and teach each other to make and use stone tools. Gorillas are averse to water, kill monkeys, are never solitary, and live only up to 9000 feet altitude. There were 5000 mountain gorillas in 1980. Colobus monkeys fight in the morning and apparently eat human body parts. Mosquitoes sting and leeches abound (the latter exist in Africa only in the film The African Queen, when Humphrey Bogart suffers from their sanguinivory). 
Impressively, Crichton provides a wide-ranging list of 65 references, mostly secondary-source books. This list must impress readers, who are entitled to think that the author has done thorough homework, but only nine of them were written by primatologists. There is no Standard Statement. There are footnotes, some of which are clearly fiction, but others apparently not. More cunning is a list of acknowledgements, in his Introduction. Some thanks are to imaginary sources of aid, such as Elliot, and even to Amy herself; others are to apparently real persons who aided Crichton in his apparently real trip to the Virungas. Who can say which are fake and which not?

Crichton is a skillful and persuasive writer of best-sellers that lend themselves to feature films. He has used his scientific and medical training to create un-put-downable, well-informed fiction. Lay readers of Congo will learn much along the way about factual primatology but will be unable to know what else is not, unless they are prepared to do a mountain of research, which seems unlikely.

\section{Brazzaville Beach, by William Boyd (1990) (BB)}

Boyd has published a string of prize-winning best-sellers, several of which were set in Africa, such as A Good Man in Africa. This one differs from all others in being focused on a specific scientific challenge, that is, to understand the nature of humanity's closest living relation, the chimpanzee. It is told through the eyes of Hope Clearwater, a young primatological field researcher. It is told in the present, by italicized, brief flashbacks, but also recounts the past; the story thus alternates between the first- and second-person viewpoint. Rarely, for the specialized genre of ape fiction, it concentrates almost entirely on ape behavior in nature, rather than in captivity. The book has a second aspect, which describes the ups and downs of her relationship with her mathematician husband, but it is irrelevant to primatology and so is ignored here.

Hope works at a long-term primatological study site, in an unnamed African country, which most closely resembles Angola (which has few wild chimpanzees). It is in civil war and has prized mineral resources being contended for by opposing factions. The project is based in Grosso Arvore National Park, headed by Eugene Mallabar, a famous, established British field primatologist and author of successful books championing wild chimpanzees. The project covers various topics, using ecological and ethological approaches, based on observational follows of apes habituated by banana provisioning. Mallabar's view of the chimpanzee is positive and engaging and dominates the research of the group. However, Hope and her field assistant, Joao, begin to find indirect evidence that all is not well with the apes, with indications of extreme aggression, even infanticide. There are injurious, and even apparently fatal, interactions between two neighboring groups, North and South, who have split apart and defend separate territories. Hope tries to inform her colleagues about this disturbing evidence, but with little success, as it contradicts the received wisdom of the leader. But things continue to worsen, as the North group's patrols make incursions into the South group's territory. Evidence emerges of cannibalism and then graphic descriptions of 'pongicide,' as the Northern males kill the Southerners, one by one. They kill not only males but females, unless the latter change their group membership. Hope is eventually forced to leave the research camp, banished for her unwelcome findings. She eventually returns, undaunted, only to encounter a grisly climactic interaction, in which Northern males gang up to finish off the last Southern male. She intervenes and shoots and kills the three chimpanzee assailants. The remainder of the book relates her travails when captured by one of the opposing groups of rebels, and the primatology is left behind.

If this somehow sounds familiar, it should. It is recycled from Jane Goodall's magnum opus, The Chimpanzees of Gombe (1986), published four years earlier. Tanzania is the country, "Grosso Arvore" is Gombe, "Mallabar" is Goodall, "Northerners" are Kasekela community and "Southerners" are Kahama community, "Duveen Foundation" is the Grant Foundation, the chief local field assistant, "Joao," is Hilali Matama, young researchers from Stanford University are young researchers from Stanford University, etc., etc. "Hope" reflects no single researcher (although I suspect that there is one) but is a clever synthesis of several. An attempt is made to murder her, perhaps recalling the mysterious death of Ruth Davis at Gombe (Peterson 2018, for review, see McGrew 2019). Many of Gombe's chimpanzees are specifically described but renamed and combined. Boyd's "Rita-Mae" and "Rita-Lu" are mother and daughter, combining characteristics of Gombe's Madam Bee and Little Bee, and Passion and Pom. As with the Bee family, the mother is killed by invaders and the daughter is recruited by them. As with Passion's family, they share in eating an infant victim with her young son, here "Lester," based on Gombe's Prof. The adult male victims of pongicide can be linked to individuals at Gombe, Boyd's "Mr Jeb" is Gombe's Goliath, "Muffin" is Sniff, "Conrad" is Worzle, etc. All of this and much more is easily documented in Goodall's book (page numbers supplied, if needed), but none of it is verbatim plagiarism.

Not surprisingly, Brazzaville Beach amounts to the most extensive and accurate description of wild chimpanzee agonism in all of fiction. It is a science fiction thriller of another sort, with a gripping unfolding of plot and a shocking climax. Readers will learn about the 'chimpanzee wars' (not to be confused with 'chimpanzee culture wars,' Langlitz 2020), and be shaken by chimpanzee nature, which is a far cry from Tarzan's Cheetah or Curious George. One wonders if Boyd 
actually spent time at Gombe, taking his own notes, but there are many minor errors that suggest not: Colobus monkeys are said to live in troupes (sic); researchers habituate themselves to apes, rather than vice versa; newborn chimpanzees are said to be hairless, while adults have fur; ants are confused with termites; researchers wear suede ankle boots, apes have a cloaca; cicadas sing; soil is lateritic, etc.

There are no accessories and no Standard Statement, just the text.

The novel was a number-one best-seller, with rapturous reviewers' comments on the book's cover, but none of these snippets mentions Goodall or Gombe. One might suppose that Boyd made a substantial financial contribution to Gombe, out of gratitude, but he did not.

\section{The Woman and the Ape, by Peter Hoeg (1996) (TWATA)}

Originally published in Danish and written in the third person, this book takes place in and around London, and with the excellent translation, seems perfectly Anglicized. The author's most notable work, at least in English, is another novel, Smilla's Sense of Snow, which was made into a feature film.

The book opens with an unspecified ape, Erasmus, being smuggled by sea into London, destined for a research laboratory but temporarily housed privately. There he meets the alcoholic wife, Madelene, of a scientist, Adam, who works at the "Institute of Animal Behaviour at the London Zoological Gardens" (Institute of Zoology, Zoological Society of London). Madelene's curiosity is aroused by Erasmus's unusual characteristics, e.g. four more teeth than expected, and she seeks taxonomic aid, but he is essentially a chimpanzee. The two get to know one another over the same time that it becomes apparent that Erasmus is destined for invasive research. Halfway through the book, she engineers his escape from captivity, and they go on the run to Hyde Park, Hampstead Heath, and eventually "St Francis Forest" (Whipsnade?), an Edenic wilderness on the outskirts of London. Only then does Erasmus reveal that he can speak English, and the two fall in love, copulate, and conceive. But they emerge from hiding to attend a key event, the gala inauguration of Adam as the director of the "New London Regent's Park Zoological Garden" (London Zoo). Erasmus suddenly bounds onto the stage, takes the podium, and begins a speech. Speaking carefully and thoughtfully, he explains that his species has tried its best to coexist with humans, via repeated attempts in various countries, but these efforts have failed, and so they are going home. 'They' in this case means 11 other apes, who emerge from the audience, revealing themselves to be pillars of the establishment and animal rights and welfare community, such as the Great Ape Project. The 12 apes and Madelene make their escape from the event, and the book's last scene has them leaving from London, on the same boat in which Erasmus arrived. The book's final line (which I will not reveal) is a corker.

The book therefore is clearly science fiction, but again not of the aliens and space travel type. Erasmus is an ape who synthesizes various aspects of living hominoids, but who comes from a Scandinavian island. His species origins are from an evolutionary branch that separated a million years ago from the other hominins in Africa and migrated north. His brain is the size of a chimpanzee's but is much more convoluted, giving him higher intelligence.

Hoeg makes no direct reference to primatologists or primatological findings about ape behavior, but Erasmus makes nests, shows typical chimpanzee locomotion, etc. Instead, the author concentrates on neurophysiological techniques, such as EEG and PET scans, to infer intelligence.

Hoeg says little about primatology but makes basic errors about primates: He says that there are 150 species of ape, when presumably he means simian primates. He says that no primates exist naturally in a temperate climate and that apes cannot tolerate eye-to-eye contact. Sometimes his natural history goes seriously awry, as when he describes western Brazil populated by warthogs, presumably when he means peccaries.

The book has no accessories and no use of the Standard Statement. However, all author royalties will go to a foundation that provides aid to Luo women and children in western Kenya (a non-great-ape habitat country), although the reason for this is not given.

In many ways, the book is the most thought-provoking of the six, with almost philosophical insights into this fantastical situation.

\section{The Evolution of Bruno Littlemore, by Benjamin Hale (2011) (TEOBL)}

This ambitious novel of 50 chapters is half-again as long as any of the others in this sample. It is a prize-winning first effort and a tour de force, written during a stint at the Iowa Writers' Workshop, which, coincidentally, is not far from the (then) Great Ape Trust, home of Kanzi et al. Hale writes with élan and a sort of engaging quirkiness, and unlike all the other books in the sample, it abounds with humor. In tone, the result somehow invokes James Toole's A Confederacy of Dunces. Hale is a wordsmith, and the text is full of obscure ones; how many of the following ten do you know: alexic, fustilug, hexadectans, pinquid, salmagundi, semantemes, tatterdemalion, thaumaturgy, trichotillamaniac, yonic? (Not to worry, the MS Word spell-checker recognized only four, and the Oxford English Dictionary, 1993, has only five.)

The book is autobiographical, a life's story written in the first person by a chimpanzee, Bruno Littlemore, dictated 
late in life to an amanuensis, Gwen Gupta. But the important female character is Dr Lydia Littlemore, a research psychologist at the University of Chicago. Born and raised in Lincoln Park Zoo, Bruno's early life is oriented to the social demands of living in a confined chimpanzee group in the Primate House. His intelligence revealed through experiments in the zoo leads to his transfer to a research laboratory headed by Norman Plumlee, under whom Lydia works. Working with Lydia, Bruno's acquisition of human language draws him closer to her, and she becomes his champion, so that eventually he is allowed to move to her home to live. This occupies the first third of the book, in daily life full of experiments and ventures out into the world of Chicago's streets. The two fall in love, have sex, and conceive, but things go awry, and Bruno is banished to a Texas animal sanctuary, where he meets other ex-research apes, such as "Noam Chompy." Now familiar with how to operate in the human world, having acquired spoken English, he manages to get back to Chicago, seeking his lost Lydia. But this leads to conflict with his old nemesis, Plumlee, with fatal results. Bruno is reprieved from trial for murder but confined for life in a secure facility, "Zastrow" (Yerkes?), in Georgia, where he has plenty of time to set down his story.

The text is chock full of science, that is, cognitive and linguistic experimental psychology. As early as page 13, a famous experiment testing imitation versus emulation using an 'artificial fruit' is invoked (à la Andrew Whiten); later come studies of token economy, photo-sorting, Skinnerian learning, American Sign Language, representational painting, gesture, exploration of novel objects, instrumental learning rewarded with M\&Ms, categorical sorting, etc. Bruno learns an artificial language resembling Yerkish, but also is able to comprehend and carry out novel but nonsensical tasks when instructed in spoken English, such as 'Put the dog in the refrigerator' (as done by Kanzi, Savage-Rumbaugh, and Lewin 1995). The scientific findings are wellsummarized and presented, with appropriate safeguards, such as the Clever Hans problem. A whole chapter (23) is devoted to the Nim Chimpsky project. Field research on wild chimpanzees is virtually ignored and not even mentioned until page 354, but exhibits at the Lincoln Park Zoo present largely accurate and detailed descriptions of Pan troglodytes and Homo sapiens (pp. 525-530).

Not surprisingly, textual reflections of actual people and places are many; some are presented accurately, others renamed. Herbert Terrace is Herbert Terrace, but the Gardners become the "Gardeners," and William Lemmon becomes "Bill Lemon." The research institute in Chicago is clearly based on its counterpart at the Yerkes Primate Center. The Texas Ranch seems based on Black Beauty ranch, where Nim Chimpsky (here called "Clever Hands") spent years. Notorious LEMSIP is referred to as NYU's research facility in Westchester. But the two most important human characters, "Lydia" and "Norm," seem remarkably like Sue Savage-Rumbaugh and Duane Rumbaugh. Oddly, given the emphasis on 'pongo-linguistics,' Roger and Debbie Fouts are never mentioned, nor is Kanzi.

Given the extensive references to primatology, it is not surprising to find errors: Chimpanzees weep in anguish, produce globular dung, sleep in one big cuddly heap, etc. Primates are said to have three primal fears: snakes, the dark, and falling backwards. However, these slip-ups are few, and none is important to the narrative.

Hale includes the Standard Statement, amazingly, given how often the text is specifically derivative. His acknowledgements are mostly as expected, but he thanks the Great Ape Trust and urges readers to learn more from their website. He pointedly praises Sue Savage-Rumbaugh and Duane Rumbaugh for their research, but it is not clear whether he ever met them. He gives thanks to Jane Goodall for an inspiring lecture. Unusually, the book contains six illustrations, all helpful drawings, such as the results of Bruno's cosmetic surgery (p. 442).

In summary, this is an impressive book, based on much research, well-blended with a compelling plot and eventful life story. Readers will learn much that is disturbing about human use of apes in captivity, which, given the lack of reference to apes in nature, was probably the author's intention, as summarized in Bruno's statement in the final sentence of the book, "...you taught me language, and my profit on it is, I know how to curse."

\section{A Beautiful Truth, by Colin McAdam (2013) (ABT)}

Another prize-winning author, McAdam has produced a double-barreled book: About half describes the home-rearing of a chimpanzee from infancy to adolescence, and it is the only one of the six novels sampled here that tackles the details of that topic. The other half of the book covers daily life in captivity, first in a laboratory, then in a captive group of chimpanzees, in a setting that is neither zoo nor lab, but somewhere in between. The format of the book alternates between these two worlds, chapter by chapter. The writing style is telegraphic, with limited punctuation; for some reason, speech is not put into quotation marks. McAdam is fond of making up but not explaining new words, such as plekter, bloning, pleen, etc.

The ape subject is "Looee," and his foster human parents are Walt and Judy, a childless married couple who live in rural Vermont. They know nothing about nonhuman primates but try their best to make a home for the wild-born, infant chimpanzee, adopted from a dubious wild animal dealer. His upbringing is chronicled from Looee's point of view, as he develops mentally and physically. He acculturates to the human lifestyle, both in and out of the house, increasingly better at communication, whether producing 
gestures or comprehending speech. However, his growing strength and rambunctiousness eventually leads to banishment, after he attacks two workmen.

Looee is quickly shunted to the Girdish Institute, in the southern USA, where the apes live singly and miserably, in racks of bare cages. They suffer both from the hellish setting and the Institute's painful and invasive biomedical research, headed by Dr Meijer, under contracts to Big Pharma. Many of his companions do not survive this treatment, but Looee is reprieved and transferred to the Institute's field station. There, the group lives in an enclosure, subject to observation and simple experiments, with little interference. Looee's ups and downs of adapting to this very different life are described in ethological detail. For example, he must cope with social challenges among conspecifics, such as dominance hierarchy. Rape is common and aggression is fatal. In the midst of this, an empathetic researcher, David, seeks to do studies of language and cognition but... The book ends with Looee resigned to his fate in this in-between world.

The home-rearing of Looee (cf. Booee from Lemmon's colony) derives heavily from Maurice Temerlin's Lucy (1975) and Vince Smith's Sophie (2004), including such events as giving a kitten to Looee, his learning to drink and smoke, learning to paint pictures, etc. His life follows the usual downward descent from the charming, dependent infant ape to increasingly unmanageable puberty, especially his sexual awakening. McAdam's treatment of 'pongo-linguistics' is a clever mix of the work of SavageRumbaugh, Terrace, and Fouts, focusing on both sign language and computerized lexigrams. Life in the chimpanzee group at the field station draws mostly on the work of Frans de Waal, both at Arnhem Zoo (1982) and Yerkes field station (e.g. 1989). Descriptions of the devastating treatment of apes in biomedical facilities are graphic and credible, but no sources are obvious. Specific studies, even classic ones such as Crawford's (1937) cooperative rope-pulling by pairs of chimpanzees at Yerkes, are used and even critiqued. The author has done his homework and weaves it together seamlessly, although psychology dominates, with little mention of biological and anthropological contributions to primatology. Almost nothing is said about chimpanzees in nature, although Jane Goodall and Rachel Weiss are acknowledged.

Such a wide range of coverage means that mistakes occur. Wild communities are termed 'colonies,' and field sites are confused (Kibale and Mahale). Grooming hand-clasp occurs only in Uganda. Individuals who do not copy others are shunned. Apes show Schadenfreude. Etc.

Specific references are easily discerned: "Girdish Institute" is Yerkes Primate Center, divided between the main biomedical center and the behavioral field station. Amongst pharmaceutical companies, "Marck" is Merck, "Pfintzer" is Pfizer, etc. Even individual chimpanzees are familiar: Mother and son Matata and Kanzi at Yerkes are "Mama and
Mr Ghoul" at Girdish, but "Mama" is also Mama, the alpha female at Arnhem (de Waal 1982, 2019). Looee's biting off part of a human's finger could refer to Jane Goodall, Jill Pruetz, Sue Savage-Rumbaugh, etc. "David" sounds a lot like Frans de Waal, but Chomsky and Terrace remain their real selves. In spite of this, McAdam offers the Standard Statement, although the book's text is full of precise resemblances to actual persons, events, organizations, and locales, as noted above. In his acknowledgement to eight primatologists, he refers to their "research and stories," but it is not made clear whether or not he ever communicated with them.

In terms of covering a wide range of environments in which chimpanzees are confined, the author offers a rich array. His lengthy and detailed imaginings of what goes on in the minds of the apes is plausible, but of course, unverifiable. His ethological descriptions of behavioral patterns and interactions are often accurate, despite his distracting neologisms, such as 'pinning' for copulation, 'chomp' for food, 'klopsiks' for testicles, etc. Accounts of reactions to the death of the alpha male, removal of the victim's testicles in pongicide, infantile interruption of mother's copulation, etc., all ring true. It's a revealing and disturbing read.

\section{We Are All Completely Beside Ourselves, by Karen Joy Fowler (2013) (WAACBO)}

This vaguely titled novel won the 2014 PEN/Faulkner Award for Fiction (USA) and was shortlisted for the 2014 Man Booker Prize (UK). Little information is given about the author in the usual way, but an essay at the book's end tells of her upbringing in Indiana, daughter of a rat-running experimental psychologist. She writes in the first person as Rosemary, who has a brother, Lowell, and a sister, Fern. Only on page 77 does the reader learn that Fern is a chimpanzee, being reared in the home of a psychologist, for developmental comparison with Rosemary. Before then, there are clues, for example, curtain-climbing, and even in the first, gripping chapter, another main character is named Harlow, which can hardly be a primatological coincidence. Confusingly, the narrative begins in the middle, rather than at the beginning, so some back-and-forth temporal agility on the part of the reader is required. During 5 years of corearing, Fern and Rosemary bond closely and share experiences of standard methods of measuring intelligence in great apes, such as photo-sorting, imitation/emulation, same/different, painting, rejection of inequity, etc. They also acquire sign language. Then, Fern mysteriously disappears, to transition from life in a human home to laboratory confinement, with its ups (e.g. teaching sign language to her offspring, à la Washoe and Loulis) and downs (just about any awful treatment that the reader can imagine). Lowell also disappears, to a clandestine life in the Animal Liberation Front, which eventually has him reconnecting with Fern. I leave 
further plot developments to the reader, having already given enough spoilers (but for more details, see McGrew 2015).

Fowler has done her homework and used her secondhand acquired knowledge of chimpanzee home-rearing and 'pongo-linguistics' to combine incidents from a host of sources. Scientific home-rearing studies such as the classic Kellogg and Kellogg (1933) comparison of Gua (ape) and son Donald (human) and the Hayes' (Hayes 1951) study of Viki are used, but also pertinent is Temerlin's (1975) modern study of Lucy (who also had a human 'brother'). Pongo-linguistic studies of Nim Chimpsky by Herb Terrace $(1987,2019)$ and of Washoe and Co. by the Gardners (1989) provide the fodder for sign language research. But most credit is given to Roger Fouts, (Fouts \& Mills 1997) who headed the Chimpanzee and Human Communication Institute (CHCI; Ellensburg, Washington). The 'villain' is Dr. "Uljevik" (William Lemmon) of the "University of South Dakota" (University of Oklahoma). More peripheral but named scientists are Harry Harlow (bad guy) and Donald Griffin (good guy). Some references are minimal, for example, Matsuzawa's studies of numeracy at Kyoto University get only one sentence.

But in contrast to captive studies, field research on chimpanzees is barely mentioned, so that classic chimpanzee traits are said to be impulsive, possessive, and demanding. Once again, they are said to live in 'troops.' Dian Fossey, Birute Galdikas, and Jane Goodall are mentioned in one sentence and are termed the "monkey girls." A field worker is said to have recorded 170 rapes over three days in field study of wild chimpanzees.

Fowler's accessories are truly extraordinary: Thirty-seven (!) admiring, short cover quotes, from the New York Times to Marie Clare to Good Housekeeping, including best-selling authors, such as Barbara Kingsolver, but (tellingly?) none from primatologists. Twenty-three suggested topics for reading groups. Three pages from Fowler on why she wrote the book. Three pages of sources of further information (e.g. documentaries and websites) and further reading (all books, no journal articles). Two pages of acknowledgements, of which three are to chimpanzees at the $\mathrm{CHCI}$, but none to primatologists. The Standard Statement is abbreviated but similar to the longer version. The pièce de résistance is a four-page afterword by Richard Wrangham, entitled Apes in the Wild, mostly about Gombe, but calling attention to the author's neglect of the first scientific home-rearing project (Ladygina-Kohts 2002).

All in all, a comprehensively researched and marketed book! American Sign Language and artificial 'languages,' such as Yerkish, are accurately presented. Ditto for homerearing and laboratory-based studies. Real-life researchers, such as William Lemmon and Roger Fouts, are uncomfortably blended. Much attention is paid to opponents of invasive research on captive apes and to their activities. But beyond the focus on pongo-linguistics, the book says little about the rest of apes' lives, either in captivity or in nature. The sibling-like relationship of Fern and Rosemary is touching and persuasive, so that by the final chapter, readers will be moved.

\section{Discussion}

\section{Use of findings of scientific primatology?}

All of the authors make use of the findings of researchers who study great apes, but to greatly varying extents. Only BB makes extensive use of field studies of chimpanzees, paraphrasing pages of detailed descriptions of events from Goodall's compendium on Gombe. In C, Amy gets returned to Africa and so is eventually rehabilitated to life among wild gorillas, but this transition merits only a few sentences. Thus, basic great ape natural history is largely ignored.

The other four books focus on captive apes, and three (ABT, WAACBO, TEOBL) develop the distorting consequences of deprived confinement and the arguments, both ethical and pragmatic, against such research. One book, TEOBL, gives insightful background into apes' lives in zoological gardens, but none makes use of the growing research literature on apes in sanctuaries or refuges, such as Chimfunshi in Zambia (Siddle 2005). Most of the books make no or only fleeting mention of the other two great ape taxa, bonobo and orangutan. Omission of the former is especially puzzling, given the prominence of published findings on the pongo-linguistics of Kanzi (e.g. Savage-Rumbaugh 1986; Savage-Rumbaugh and Lewin 1995).

In most cases, authors of the novels say little about their primatological sources. The welcome exception is WAACBO, with its annotated list of websites; e.g., it is the only book to refer to another branch of pongo-linguistics, that of the Premacks (1983), with the chimpanzees, Sarah and Co., using magnetized symbolic objects. At the other extreme are TWATA and BB, which say nothing whatsoever about their source(s), despite heavily drawing upon Goodall. However, it should be said that most of the researchers whose work is used do not publish in mainstream primatological journals or would even classify themselves as primatologists in any substantial sense. Most of them are psycho-linguists or cognitive psychologists focusing on human-nonhuman experimental comparisons. This narrow focus does not stop the authors from generalizing about the ape species involved, even to the extent of detailed inferences about the apes' mental and emotional states (TWATA, TEOBL, ABT). Finally, at least according to their acknowledgements, none of the authors communicated with the primatologists on whose work they depended. 


\section{Aspects or topics of primatological findings used?}

Overwhelmingly, the emphasis in all the books is on language, with all other topics combined taking less of the authors' attention. Thus, pongo-linguistics rules! All were published after the decade of great interest in the revelations that captured both scientific and popular interest. That heyday can be demarcated by its onset in the Gardners' (1969) initial report, describing the communicatory feats of Washoe, to its crash, resulting from the disappointingly limited findings from studies of Nim Chimpsky, as reported by Terrace (1979, but see also Hess 2008). Both of these landmarks report on the teaching of an actual human language of the deaf, American Sign Language (ASL), to a nonhuman species, which dominated debate. Other research on ASL and apes, involving gorilla, Koko (Patterson and Linden, 1982), and orangutan, Chantek (Miles 1990), is not mentioned, so chimpanzees predominate. Pongo-linguistic research continued after 1979, especially using Yerkish, an artificial language, exploiting pictograms in computerized, inter-species communication via keyboard, focused on Kanzi (Savage-Rumbaugh1986; Savage-Rumbaugh and Lewin 1995), but also ASL (Fouts and Mills 1997), but mainly it has fizzled out.

Complex cognition ('intelligence') occupies a distant second place in the authors' writings. Basically, language is meant to allow access to the mentality of the apes, a crucial correlation for the researchers and for the readers of the novels. In some of the books (TEOBL, WAACBO), the authors give detailed precis of the experiments and of their significance. Classic experiments (however anecdotal and uncontrolled) are repeatedly invoked: Hayes and Hayes (Hayes 1951) taught Viki the concept of 'same' versus 'different,' then asked her to sort photographs of humans and apes in two such piles. Into the stack of photos, they inserted a photo of herself, which she then placed in the human pile. Whether this was just a perceptual error or an insight into her concept of self resulting from her human home-rearing remains unclear. Other aspects of behavior that occupy prominent positions in ape research, and which have proven implications for cognition, are ignored. Problem-solving via tool-making and tool use, whether experimentally induced in captivity or spontaneously shown in nature, is conspicuously absent, except in TEOBL. Similarly, exciting findings in cultural primatology, whether cumulative or not, are unmentioned.

Sex also features, often between Homo and Pan, with conception (hybridization), thus providing the answer to the eternal question, 'Could it happen (despite the two genera having different numbers of chromosomes)?' 'Yes, it could, in fiction.' In two cases, here (TWATA, TEOBL), it is male Pan who mates with female Homo, but in other novels, such as Collier (1931), it is the reverse. In C, we know not which sex mated with which.

Coverage of the social lives of great apes varies greatly. $\mathrm{BB}$ has long and detailed descriptions of some of its spectacular manifestations, such as pongicide and cannibalism, as parroted from Goodall's Gombe. TEOBL has similarly detailed descriptions of stressful daily life in a small zoo group, focusing on dominance and violence, apparently derived largely from de Waal's observations at Arnhem Zoo, and in his semi-natural colony at Yerkes Field Station. ABT describes the limited but important impoverished relationships that can exist in a biomedical facility, even with the apes housed individually.

\section{Accurate use of primatological knowledge?}

The extent to which authors are accurate in their depiction of the apes varies from the trivial to the important. For example, all of the books describe the social unit of the chimpanzees and gorillas as the 'troop.' However, no great apes live in troops; instead, chimpanzees and bonobos live in communities/unit-groups, gorillas in polygynous families, and orangutans are mostly solitary. Troops are for monkeys. Where the authors got this label is unknown, as no primatologist uses it for apes. Does this really matter? Maybe not, but it suggests that there is a fundamental misunderstanding, unaware of the profound significance of social relationships that are based on community or kinship. This lumping of nonhuman primates is more seriously and explicitly manifest in TWATA, when 150 species of apes are claimed to exist. First-year undergraduates would spot this error. Even if the author is counting all ape taxa that have ever lived, extinct and extant, that total is far less. This error is egregious, especially as we are living in the twilight of the ape evolutionary radiation, likely to go extinct in nature in the present century.

On the other hand, descriptions of research on pongolinguistics are mostly accurate. The authors have done their reading of the scientific literature, at least in secondary sources, but it now is outdated. Absent is any discussion of the limitations of that research, as it eventually unfolded (Krause and Beran 2020). Three of the novels were published more than 20 years after the decline in pongo-linguistics, which was very much a twentieth century phenomenon, yet they contain no hints as to the paradigm's demise.

In reality, all the studies of pongo-linguistic communication between humans and other apes simultaneously employed English, spoken by the experimenters. Thus, apes comprehend the meaning of speech but do not produce it in the same modality. This combination has not led to any ape acquiring spoken human language, despite sustained and prolonged efforts by researchers. However, in two of the books (TWATA, TEOBL), the apes do speak English: in TWATA, Erasmus delivers an address to a scientific 
conference, and in TEOBL, Bruno dictates his autobiographical recollections to an amanuensis. However, this precious form of communication is reserved exclusively for human-ape interaction in the novels, not for use among the apes.

The accuracy of the recounting of cognitive psychological experimentation is also impressive, although the examples are few and appear (necessarily?) cherry-picked. The authors seem to have accepted them as given, that is, how they were received at the time, even decades ago, without taking account of advances in primatology that have called some of them into question.

There seems to be no correlation between the accuracy of the novels' contents and the success of the books. Similarly, the range and extent of accessories from none (BB) to profuse (WAACBO) seems to have made no difference to success, nor does the inclusion or not of the Standard Statement, which must be confusing to readers.

\section{Conclusions}

These novels are fiction, by definition, and even those that include the Standard Statement on the reverse side of the title page therefore claim to bear no relation to reality. However, all the novels refer to actual persons, events, institutions, etc., or disguise them with such slight modification that their actual source in the real world is evident. All the novels purport to be science fiction, that is, while referring to actual primatology and primatologists, they are not confined by the limitations of scientific knowledge. Instead, they are entitled to be free to go beyond them, wherever the authors' imaginations take them. After all, that is artistic license! Does it matter if they mislead the reader by omission or commission, by intention or accident or misunderstanding? Perhaps not, for after all, a novel is storytelling, not a textbook. But what if the contents of such a novel are read by orders of magnitude more readers than would ever read an academic monograph or nonfiction equivalent of a novel, much less a scientific journal article? Some of these novels were best-sellers, and so must have had a big impact on readers' beliefs about apes, and so millions of readers may be misinformed.

Much of what is found in these novels could have been made more accurate (and exciting?) if it were better informed. There is a simple solution to this quandary: Primatologists could be more aware of their potential contribution to an area of scholarship outside their academic boundaries and so be open, perhaps even proactive, to such interaction. Similarly, novelists could consult with scientists, not to be chided or censured, but to have more up-to-date and complete information to work with. (This paper was written after I was approached by such an intending author, who sought such consultation, and which transpired gratis, hopefully to our mutual benefit.)

Acknowledgements I thank: Jim Anderson, Cat Hobaiter, and Andrew Whiten for sharing books or providing information about them and for comments on the manuscript; Marion Copeland for her immensely helpful and comprehensive annotated bibliography of sources of primates in fiction; perverse thanks to COVID-19, which provided the enforced free time to pursue this project.

\section{References}

Boyd W (1990) Brazzaville beach. Penguin Books, London, p 398

Brown L (1993) The new shorter Oxford English dictionary, vol 2. Clarendon Press, Oxford, p 3801

Collier J (1931) His monkey wife, or married to a chimp. Oxford University Press, Oxford (reprinted 1983)

Copeland M (2015) Apes of the imagination: A bibliography. Animalsandsociety.org/human-animal-studies/ apes-of-the-imagination-a-bibliography

Crawford MP (1937) The cooperative solving of problems by young chimpanzees. Comp Psychol Monogr 14:1-88

Crichton M (1980) Congo. Alfred A Knopf, New York, p 348

de Waal FBM (1982) Chimpanzee politics. Jonathan Cape, London

de Waal FBM (1989) Food sharing and reciprocal obligations among chimpanzees. J Hum Evol 18:433-459

de Waal FBM (2019) Mama's last hug. Granta, London

Fouts RD, Mills ST (1997) Next of kin: my conversations with chimpanzees. Avon, New York

Fowler KJ (2013) We are all completely beside ourselves. Serpent's Tail, London, p 329

Gardner RA, Gardner BT (1969) Teaching sign language to a chimpanzee. Science 165:664-672

Gardner RA, Gardner BT, van Cantfort TE (1989) Teaching sign language to chimpanzees. SUNY Press, Albany, NY

Goodall J (1986) The chimpanzees of Gombe. Harvard University Press, Cambridge, MA

Hale B (2011) The evolution of Bruno Littlemore. Atlantic Books, London, p 578

Hayes C (1951) The ape in our house. Harper, New York

Hess E (2008) Nim Chimpsky: the chimp who would be human. Bantam, New York

Hoeg P (1996) The woman and the ape. Farrar Straus and Giroux, New York, p 262

Kellogg WN, Kellogg LA (1933) The ape and the child. McGraw-Hill, New York

Krause MA, Beran MK (2020) Words matter: reflections on language projects with chimpanzees and their implications. Am J Primatol 82:e23187

Ladygina-Kohts N (2002) Infant chimpanzee and human child. de Waal FBM (ed) Oxford University Press, Oxford

Langlitz N (2020) Chimpanzee culture wars. Princeton University Press, Princeton, NJ

McAdam C (2013) A beautiful truth. Granta, London, p 292

McGrew WC (2015) Review of: we are all completely beside ourselves. Primate Eye 117:24-26

McGrew WC (2019) Review of the ghosts of Gombe. Primates 59:571-572

Miles HL (1990) The cognitive foundations for reference in a signing orangutan. In: Parker ST, Gibson KR (eds) "Language" and intelligence in monkeys and apes: comparative developmental perspectives. Cambridge University Press, Cambridge, pp 511-539

Patterson FG, Linden E (1982) The education of Koko. Holt, New York 
Peterson D (2018) The ghosts of Gombe. A true story of love and death in an African wilderness. University of California Press, Oakland, CA

Premack A, Premack D (1983) The mind of an ape. Norton, New York Savage-Rumbaugh ES (1986) Ape language: from conditioned response to symbol. Columbia University Press, New York

Savage-Rumbaugh ES, Lewin R (1995) Kanzi: The ape at the brink of the human mind. John Wiley \& Sons, New York

Siddle S (2005) My family tree. A life with chimpanzees. Grove Press, New York

Smith V (2004) Sophie. Raising a chimp in the family. De Capo Press, Boston
Temerlin M (1975) Lucy: growing up human. Science and Behavior Books, Palo Alto, CA

Terrace HS (1987) Nim: a chimpanzee who learned sign language. Columbia University Press, New York

Terrace HS (2019) Why chimpanzees can't learn language and only humans can. Columbia University Press, New York

Publisher's Note Springer Nature remains neutral with regard to jurisdictional claims in published maps and institutional affiliations. 